\title{
DIABETES RESILIENCE TRAINING ON SELF-CARE, GLYCEMIC CONTROL, AND DIABETES BURNOUT OF ADULT TYPE 2 DIABETES MELLITUS
}

\author{
Hidayat Arifin ${ }^{1}$, Kusnanto ${ }^{2 *}$, Erna Dwi Wahyuni ${ }^{3}$, Rifky Octavia Pradipta ${ }^{4}$ \\ ${ }^{1,2,3,4}$ Faculty of Nursing, Airlangga University, Surabaya \\ Email*: kusnanto@fkp.unair.ac.id
}

\begin{abstract}
Introduction: Treatment that must continue, control, and diet that must be obeyed by people with DM can cause boredom (burnout) - inability to care for themselves, and blood sugar that is not controlled. The purpose of this study was to determine the effect of diabetes resilience training on self-care, glycemic control, and diabetes burnout of adult type 2 diabetes mellitus. Methods: This study was a quasi-experimental design. The total samples were 70 respondents (treatment and control) obtained by cluster sampling. The independent variable was diabetes resilience training and dependent variables were self-care, glycemic control, and diabetes burnout. The intervention provided for one month with four meetings. Instrument used self-care questionnaire of Self-Care Inventory-Revised (SCI-R), glycemic control questionnaire used an observation sheet for fasting blood sugar, and diabetes burnout questionnaire used Diabetes Distress-Screening Scale (DDS17). Data were analyzed with Wilcoxon signed ranks test, Mann Whitney U Test, Independent-sample t-test, and 1-Sample K-S. Results: There was an effect of diabetes resilience training on self-care $(p=0.003 ; p<0.05)$, glycemic control $(p=0.020 ; p<0.05)$, and diabetes burnout $(p=0,000 ; p<0.05)$. Conclusions: Diabetes resilience training provided by researchers to respondents can improve good self-care behavior, decreased glycemic control values, and decreased distress (diabetes burnout) in adult type 2 diabetes mellitus. Based on the results, it is recomandation to nurses and health care provider to implementation the diabetes resilience training regularly.
\end{abstract}

Keywords: diabetes burnout; glycemic control; resilience; type 2 diabetes mellitus; self-care

\section{INTRODUCTION}

Type 2 Diabetes Mellitus (T2DM) is a metabolic disease characterized by an increase in blood sugar levels, and this occurs because of abnormalities in insulin secretion, insulin action or both (Kusnanto, 2017). T2DM is one of the most chronic diseases experienced by people in the world (Lefrancois, Mehta, Sullivan, Lin, \& Glazebrook, 2017). T2DM patients are susceptible to nerve and vascular damage which can result in loss of protective sensation in the legs, poor circulation, biomechanical changes in foot and skin trauma (Fan, 2012). This can be caused by lack of ability to care for themselves and uncontrolled blood sugar levels (Schaper et al, 2017). In addition, patients with T2DM are very susceptible to distress due to the continuous treatment and diet that must be followed (Swoboda, Miller, \& Wills, 2017). Complications related to T2DM constitute a significant cause of morbidity and mortality and have a severe impact on patients' quality of life (Hsieh, Lee et al, 2016).

$\mathrm{T} 2 \mathrm{DM}$ is one of the chronic diseases that often occur in the community. The International Diabetes Federation (IDF) states that the prevalence of T2DM in the world is
$1.9 \%$ and has made T2DM as the seventh leading cause of death in the world. The incidence of $\mathrm{T} 2 \mathrm{DM}$ is expected to increase again by $165 \%$ in the year (ADA, 2014). The number of diabetics in Indonesia is 8.5 million, placing Indonesia 7 th out of 10 countries with the highest number of people with diabetes. It is estimated that in 2035 the global prevalence of T2DM will increase to nearly 600 million (Shearman \& Rawashdeh, 2016). The data from the Baseline Health Research of Indonesia showed that T2DM patients aged $\geq 15$ years in 2013 had an incident rate of $6.9 \%$. This increased in 2018 to become $8.5 \%$. The prevalence was higher in women at $12.7 \%$ than in men at $9 \%$. The T2DM patients who did not take medicine made up $11 \%$ (National Institute of Health Research and Development Indonesia, 2018).

The behavior of T2DM sufferers is influenced by healthy and sick behavior. T2DM sufferers must undergo continuous and controlled treatment of medical treatment, activities, and diets that can last long. This can affect the resistance of T2DM sufferers in undergoing therapy (Hilliard, Iturralde, Weissberg-Benchell, \& Hood, 2017) and treatment (J. Y. Kim et al., 2019; Martinez, Sherling, \& Holley, 2019; Nawaz et al., 2017). 
This is caused because they have to undergo treatment throughout their lives so that their roles and functions in both the family and the community cannot be fulfilled optimally.

People with type II diabetes also may not be able to survive in a painful state, so that patients are not enthusiastic about living life, and even unable to look for the positive side of the situation they are experiencing (G. M. Kim, Lim, Kim, \& Park, 2019). This positively will affect the management of diabetes he suffered. Diabetes cannot be cured can only be managed (Alhaik, Anshasi, Alkhawaldeh, Soh, \& Naji, 2019; Wilson, McNaughton, Meyer, \& Ward, 2017). Therefore, sufferers need good resilience to help manage psychological distress due to chronic diseases such as type II diabetes. Resistance is the resilience of individuals in experiencing various difficulties to continue to be able to develop themselves in various aspects of life (Stefanic, Caputi, Lane, \& Iverson, 2015).

The most previous research interventions of T2DM were increase knowledge, behavioral and dietary adherence (Jannoo \& Mamode Khan, 2019; Wiardani \& Moviana, 2015). In this study, researcher focused on intervention that increased resilience. Resilience can be interpreted as a psychological endurance that is flexible in responding or changing situational demands and the ability to bounce back from negative emotional experiences (Masten, 2001; Steinhardt et al., 2015). Diabetes resilience training as an effort to increase the motivation and endurance of T2DM sufferers in undergoing treatment. Diabetes resilience training can be done by providing education to respondents with Diabetes Self-Management Education (DSME) to increase determination and adaptability, gymnastic to increase endurance and activity, and psychosocial training to increase recuperabilty. These combination treatments more effective to increase resilience of adult T2DM (Taormina, 2015). Based on the description above, researchers are interested in research to determine the effect of diabetes resilience training on self-care, glycemic control and diabetes burnout in adult type 2 diabetes mellitus.

\section{METHODS}

\subsection{Design}

The design in this study used a quasiexperimental pretest-posttest with control group design.

\subsection{Setting and location}

Determination of sample size used $\mathrm{G}$ *

Power 3.1.9.2 application and the results obtained as many as 35 sample sizes. The required sample size were 70 respondents, with the division of each group, namely control and intervention, were 35 respondents obtained by cluster sampling with inclusion criteria, namely 1) Respondents with a diagnosis of Type 2 Diabetes Mellitus; 2) Respondents with a diagnosis of Type $2 \mathrm{DM}>5$ years; 3) Age of respondents 25-65 years; 4) Respondents can read and write; 5) Minimum education of elementary school; 6) Respondents do not experience vision and hearing problems.

The independent variable in this study is the effect of Diabetes resilience training and the dependent variable in this study are SelfCare, Glycemic Control, and Diabetes Burnout in Type 2 Diabetes Mellitus Patients. This research conducted in two Health Primary Care in Surabaya, East Java, Province Indonesia. This research was conducted in May - September 2019.

Treatment group given interventions of diabetes resilience training by providing DSME to increase determination and adaptability, gymnastic to increase endurance and activity, and psychosocial training with guide discussion to increase recuperabilty and strengthen each other in the process of treatment and therapy. In the treatment group given module as diabetes resilience training module developed by researcher. Diabetes resilience training involved researchers and nurses from the Health Primary Care. So that in the future, this intervention can be carried out continuously. The research conducted for four weeks with four meetings. So that every week conducted intervention one meeting with respondents. Control group given intervention as Health Primary Care Programs namely: Chronic Disease Management Program (Prolanis). The intervention providing health education and gymnastic. In the control group given module as diabetes resilience training module after research has finished. Pre-post data were taken before and after the intervention, at the first week and fourth week. 1.3 Instrument/measurements

\subsubsection{Self-care}


The self-care questionnaire uses SelfCare Inventory-Revised (SCI-R) from (La Greca, 2004). Consists of 14 questions consisting of Diet (4); Glucose monitoring (2); Treatment (3); Exercise (1); Glucose level (2); Prevention (3). Good Scoring: $\geq$ mean; Less: $\leq$ mean.

\subsubsection{Glycemic control}

The glycemic control questionnaire uses an observation sheet for fasting blood sugar. Normal score Good: 80-100 mg / dl, Medium: 101-125 mg / dl, Poor: $\geq 126 \mathrm{mg} / \mathrm{dl}$.

\subsubsection{Diabetes burnout}

Diabetes burnout questionnaire using

Diabetes Distress-Screening Scale (DDS17) (Fisher, Glasgow, Mullan, Skaff, \& Polonsky, 2008). The questionnaire consisted of 17

questions. Likert scale (1-6) Mild distress: <2.0; Moderate distress: 2.0-2.9; Severe distress: $\geq 3.0$.

\section{$1.4 \quad$ Analysis}

In this study, the data were analyzed using the IBM SPSS 25 application (SPSS, 2019). Data analysis used the Wilcoxon signed ranks test, Mann-Whitney $\mathrm{u}$ test, and Independent-samples t-test with a significance level $(\mathrm{p}<0.05)$.

1.5 Ethical considerations

This research has been conducted an ethics test at the Health Research Ethics Commission in Faculty of Nursing Universitas Airlangga with No. 1485-KEPK on June 12, 2019.

\section{RESULTS}

Table 1. Demography characteristic $(\mathrm{N}=70)$

\begin{tabular}{|c|c|c|c|c|}
\hline \multirow[t]{2}{*}{ Characteristic } & \multicolumn{2}{|c|}{$\begin{array}{l}\text { Treatment } \\
\quad(n=35)\end{array}$} & \multicolumn{2}{|c|}{ Control $(n=35)$} \\
\hline & $\mathbf{n}$ & $\%$ & $\mathbf{n}$ & $\%$ \\
\hline \multicolumn{5}{|l|}{ Age } \\
\hline 26-35 years & 5 & 14.3 & 4 & 11.4 \\
\hline $36-45$ years & 22 & 62.9 & 17 & 48.6 \\
\hline $46-55$ years & 7 & 20 & 13 & 37.1 \\
\hline 56-55 years & 1 & 2.9 & 1 & 2.9 \\
\hline \multicolumn{5}{|l|}{ Gender } \\
\hline Male & 9 & 25.7 & 7 & 20 \\
\hline Female & 26 & 74.3 & 28 & 80 \\
\hline \multicolumn{5}{|l|}{ Level education } \\
\hline No school & 1 & 2.9 & 5 & 14.3 \\
\hline Primary school & 3 & 8.6 & 9 & 25.7 \\
\hline Junior high school & 13 & 37.1 & 10 & 28.6 \\
\hline Senior High School & 15 & 42.9 & 8 & 22.9 \\
\hline Diploma & 3 & 8.6 & 3 & 8.6 \\
\hline \multicolumn{5}{|l|}{ Marital status } \\
\hline Not married & 6 & 17.1 & 5 & 14.3 \\
\hline Married & 23 & 65.7 & 25 & 71.4 \\
\hline Widow/widower & 6 & 17.1 & 5 & 14.3 \\
\hline \multicolumn{5}{|l|}{ Length of sick } \\
\hline$<1$ year & 3 & 8.6 & 6 & 17.1 \\
\hline $2-5$ years & 19 & 54.3 & 12 & 34.3 \\
\hline 6-9 years & 13 & 37.1 & 17 & 48.6 \\
\hline \multicolumn{5}{|c|}{ Distance from home to Health Primary Care } \\
\hline $1-5 \mathrm{KM}$ & 22 & 62.9 & 24 & 68.6 \\
\hline $6-10 \mathrm{KM}$ & 13 & 37.1 & 11 & 31.4 \\
\hline
\end{tabular}

The results in table 1 show that the majority of respondents' ages in both groups were in the range of 36-45 years. The majority of respondents in both groups were women. The education level in the treatment group is the majority of high school and in the control group is junior high school. In both groups the majority of respondents had a married couple (married). The treatment group showed that most respondents suffered from T2DM for 2-5 
years, while in the control group for 6-9 years.

the health facility is in the range of $1-5 \mathrm{KM}$.

The distance of the respondent's house with

Table 2. The effect of Diabetes resilience training on self-care, glycemic control and diabetes burnout in adult type 2 diabetes mellitus $(\mathrm{N}=70)$

\begin{tabular}{|c|c|c|c|c|c|c|c|c|}
\hline \multirow{3}{*}{ Variable } & \multicolumn{4}{|c|}{ Treatment $(n=35)$} & \multicolumn{4}{|c|}{ Control $(n=35)$} \\
\hline & \multicolumn{2}{|c|}{ Pretest } & \multicolumn{2}{|c|}{ Posttest } & \multicolumn{2}{|c|}{ Pretest } & \multicolumn{2}{|c|}{ Posttest } \\
\hline & $\mathbf{n}$ & $\%$ & $\mathrm{n}$ & $\%$ & $\mathrm{n}$ & $\%$ & $\mathbf{n}$ & $\%$ \\
\hline \multicolumn{9}{|l|}{ Self-care } \\
\hline Well & 15 & 21.4 & 21 & 30 & 16 & 22.9 & 20 & 28.6 \\
\hline Moderate & 20 & 28.6 & 14 & 20 & 19 & 27.1 & 15 & 21.4 \\
\hline $\mathrm{p}^{*}$ & \multicolumn{4}{|c|}{0.003} & \multicolumn{4}{|c|}{0.129} \\
\hline $\mathrm{p}^{* *}$ & \multicolumn{8}{|c|}{0.030} \\
\hline Mean \pm SD & \multicolumn{2}{|c|}{$54.77 \pm 9.347$} & \multicolumn{2}{|c|}{$59.37 \pm 8.349$} & \multicolumn{2}{|c|}{$47 \pm 4.466$} & \multicolumn{2}{|c|}{$47.8 \pm 3.151$} \\
\hline $\operatorname{Min} \pm \operatorname{Max}$ & \multicolumn{2}{|c|}{$40 \pm 57$} & \multicolumn{2}{|c|}{$41 \pm 74$} & \multicolumn{2}{|c|}{$40 \pm 59$} & \multicolumn{2}{|c|}{$40 \pm 57$} \\
\hline \multicolumn{9}{|l|}{ Glycemic Control } \\
\hline Well & - & - & - & - & 1 & 1.4 & 3 & 4.3 \\
\hline Moderate & 11 & 15.7 & 10 & 14.3 & 9 & 12.9 & 10 & 14.3 \\
\hline $\mathrm{Bad}$ & 24 & 34.3 & 25 & 35.7 & 25 & 35.7 & 22 & 31.4 \\
\hline $\mathrm{p}^{*}$ & \multicolumn{4}{|c|}{0.020} & \multicolumn{4}{|c|}{0.213} \\
\hline $\mathrm{p}^{* *}$ & \multicolumn{8}{|c|}{0.011} \\
\hline Mean \pm SD & \multicolumn{2}{|c|}{$\begin{array}{c}170.99 \pm \\
71.911\end{array}$} & \multicolumn{2}{|c|}{$\begin{array}{c}151.86 \pm \\
45.794\end{array}$} & \multicolumn{2}{|c|}{$162 \pm 69.292$} & \multicolumn{2}{|c|}{$\begin{array}{c}174.40 \pm \\
80.225\end{array}$} \\
\hline $\operatorname{Min} \pm \operatorname{Max}$ & \multicolumn{2}{|c|}{$107 \pm 342$} & \multicolumn{2}{|c|}{$101 \pm 295$} & \multicolumn{2}{|c|}{$94 \pm 393$} & \multicolumn{2}{|c|}{$89 \pm 432$} \\
\hline \multicolumn{9}{|l|}{ Diabetes Burnout } \\
\hline Distress mild & 4 & 5.7 & 20 & 28.6 & 1 & 1.4 & 4 & 5.7 \\
\hline Distress moderate & 5 & 7.1 & 11 & 15.7 & 11 & 15.7 & 19 & 27.1 \\
\hline Distress weight & 26 & 37.1 & 4 & 5.7 & 23 & 32.9 & 12 & 17.1 \\
\hline $\mathrm{p}^{*}$ & & & & & & & & \\
\hline $\mathrm{p}^{* * *}$ & & & & & & & & \\
\hline Mean \pm SD & & & & $\begin{array}{l}4 \pm \\
669\end{array}$ & & $\begin{array}{l}4 \pm \\
644\end{array}$ & & $\begin{array}{l}7 \pm \\
21\end{array}$ \\
\hline $\operatorname{Min} \pm \operatorname{Max}$ & 1.82 & 5.29 & 1.18 & 3.94 & & .76 & 1.2 & 5.71 \\
\hline
\end{tabular}

*Wilcoxon signed ranks test;

**Mann-Whitney u test;

***Independent-samples t-test;

Significantly $(\mathrm{p}<0.05)$

The results of the study in Table 2 show that there is a change in good self-care in the treatment and control groups. The analysis showed that the treatment group experienced significant changes in self-care $(p=0.003 ; p$ $<0.05)$ and there were differences in self-care between the two groups (treatment and control) $(p=0.030 ; p<0.05)$. From these results, it can be seen that the intervention given by the researcher can change the respondent's self-care to good.

Research results on the glycemic control variable of fasting plasma glucose in the treatment group with moderate-bad characteristics, while in the control group with good, moderate, and bad characteristics. The results of the analysis showed that the treatment group experienced changes in glycemic control of fasting plasma glucose ( $p$ $=0.020 ; \mathrm{p}<0.05$ ) and the minimum and maximum values of glycemic control decreased at posttest $(107 \pm 342 ; 101 \pm 295)$. The analysis also showed that there was a significant difference $(\mathrm{p}=0.011 ; \mathrm{p}<0.05)$ glycemic control of fasting plasma glucose in the treatment group and the control group. From the results of this study, it can be seen that diabetes resilience training can change respondent behavior that can be assessed from changes in glycemic control. 
The results of the study on diabetes burnout variables are known that the majority of respondents in the treatment and control groups experienced severe distress. The analysis showed that the treatment group showed very significant changes in diabetes burnout (severe - mild distress) ( $p=0,000 ; p$ $<0.05)$. Diabetes burnout score in the treatment group (pretest-posttest) experienced a decrease $(1.82 \pm 5.29 ; 1.18 \pm 3.94)$ than in the control group. The analysis also showed that there were differences in diabetes burnout in the treatment and control groups $(\mathrm{p}=0.017$; $p<0.05)$. From these results it can be seen that interventions with diabetes resilience training can reduce the level of distress (diabetes burnout) in T2DM patients.

\section{DISCUSSIONS}

The results of this study indicate that Diabetes resilience training is effective in increasing self-care, glycemic control, and reducing diabetes burnout. The positive effect of diabetes resilience training can be used to develop individual abilities in managing their health. This is supported by research conducted by (Steinhardt et al., 2015) which states that resilience helps one to keep thinking positive, not giving up and adding to the ability to control and handle life's difficulties.

People with diabetes are very susceptible to complications that can reduce the quality of life (Shao, Yang, Fonseca, Stoecker, \& Shi, 2019). The risk of complications can be reduced by increasing self-care. Good self-care helps people with diabetes pay more attention to blood sugar control (Ebrahimi, Sadeghi, Amanpour, \& Vahedi, 2016). Self-care behavior is defined as an activity that can improve the quality of life and satisfaction of people with diabetes (White et al., 2015). Self-care also helps people with diabetes not only to control, but also monitor their lives (Bruno, Choi, Thorpe, \& Yu, 2019). One of the diabetes resilience training activities is the strengthening of health education that has been obtained from health centers and hospitals where the client controls. This strengthening aims to evaluate, assess and map which clients still lack resilience. Enhancement is then carried out jointly with other clients by providing self-care education doing antidiabetic and anti-stroke exercises together. Previous research states that self-care education improves the health of patients with DM (Chery, 2018). The control group did not experience changes in self-care despite participating in Chronic Disease Management Program (CDMP) activities. This can be caused because self-efficacy is not formed in the control group. One reason is the client who has been suffering from diabetes for too long (Dehghan, Charkazi, Kouchaki, \& Zadeh, 2017).

This research shows that diabetes resilience training can improve glycemic control. This is based on self-care that is formed will bring self-awareness to sufferers to pay more attention to their health (Gupta et al., 2017). Diabetes resilience training invites people with diabetes to record and evaluate blood sugar levels after control routinely. Diabetics' self-awareness is improved by reviewing their blood sugar records. For patients who do not have a blood sugar record, the researcher will provide it for safekeeping. For those who already have but are not well recorded or even confused about how to read the notes, the researcher helps to explain along with other sufferers with a well-documented blood sugar record. During the diabetes resilience training process, researchers always try to invite people with diabetes to make themselves aware that their health is the responsibility of each individual, not the health center or hospital and even family. Because in principle the three aspects are supporters who can effectively make an impact if the main elements of the client as individuals are also cooperative in maintaining their health.

This is consistent with research showing that patients who are communicative and critical of health conditions tend to be more active and able to modify the situation (Lee et al., 2016). The control group did not experience changes in glycemic control because there were still many clients who did not pay attention to their blood sugar history and its implications for daily life. Including eating patterns (diet), physical activity and medication (Watkins, Quinn, Ruggiero, Quinn, \& Choi, 2013). Strengthening interventions through diabetes resilience training directly affects health awareness and indirectly influences self-efficacy through support and guidance from health workers. Diabetes resilience training also indirectly influences self-care behavior through mediation of blood sugar recording and self-efficacy. Self-efficacy 
and self-care behavior relatively affect glycemic control. Perceived empowerment and health awareness moderately change selfefficacy and self-care behavior (Papatheodorou, Banach, Bekiari, Rizzo, \& Edmonds, 2018).

A long course of illness and complex health management can make patients with DM feel very tired and hopeless (Dehghan et al., 2017). Burnout in diabetic patients can be interpreted as a condition of stress in patients who last long accompanied by frustration. This condition can be a cause for the client to not comply with the given regimen. This can be exacerbated by unstable emotional involvement over failure to follow the regimen even though the patient has tried to adhere to the advice given (S. Abdoli, Hessler, Vora, Smither, \& Stuckey, 2019). Burnout can also be caused by lack of support systems, lack of knowledge, fear of diabetes and lifestyle changes (Wingert, Johnson, \& Melton, 2015). Burnout can also be interpreted as a negative psychosocial phase, characterized by physical and mental fatigue for DM treatment, unable to control oneself, being helpless and trapped in fatigue due to diabetes, supported by other factors that have the potential to cause fatigue due to diabetes (Samereh Abdoli, Jones, Vora, \& Stuckey, 2019). In the control group, burnout syndrome can be reduced because in diabetes resilience training researchers invite fellow sufferers to support each other both physically and mentally. Clients are given tips and tricks to encourage fellow sufferers who seem to be losing enthusiasm. This condition is not only in terms of behavior but also words. Choose words so as not to offend and motivate other sufferers. In contrast to the control group, burnout cannot be detected because the focus of treatment is only in physical terms not touching psychological and emotional aspects.

\section{CONCLUSIONS}

Diabetes resilience training provided by researchers to respondents can improve good self-care behavior, the value of decreased glycemic control, and reduced distress (diabetes burnout) in adult type 2 diabetes mellitus. The intervention of diabetes resilience training conducted regularly is proven to have a positive impact on respondents. Based on the results, it is recomand to nurses and health care provider to implementation the diabetes resilience training regularly.

Research locations in both groups are in the area of the Chronic Disease Management Program (Prolanis) so that respondents have been exposed to CDMP interventions such as health education, medical adherence, medical attention, and activities. Researchers try to reduce bias by providing different and reinforcing interventions to increase respondents' resilience. Diabetes resilience training provided in this study for one month with four meetings. The results of this study will be better if the application of the intervention in a long time.

The researcher would like to thanks to The Association of Indonesian Nurse Education Center (AINEC) for participating and funding suppor with No. 208/AINEC.Ka.Sr/V/2019, the research locations who helped and facilitated the research.

\section{REFERENCES}

Abdoli, S., Hessler, D., Vora, A., Smither, B., \& Stuckey, H. (2019). Descriptions of diabetes burnout from individuals with Type 1 diabetes: an analysis of YouTube videos. Diabetic Medicine, 1-8. https://doi.org/10.1111/dme.14047

Abdoli, Samereh, Jones, D. H., Vora, A., \& Stuckey, H. (2019). Improving Diabetes Care: Should We Reconceptualize Diabetes Burnout? The Diabetes Educator, 45(2), 214-224. https://doi.org/10.1177/01457217198290 66

ADA, (American Diabetes Associatin). (2014). Standards of Medical Care in Diabetes 2014. Diabetes Care2, 37(1), S14.

Alhaik, S., Anshasi, H. A., Alkhawaldeh, J., Soh, K. L., \& Naji, A. M. (2019). An assessment of self-care knowledge among patients with diabetes mellitus. Diabetes and Metabolic Syndrome: Clinical Research and Reviews, 13(1), 390-394.

https://doi.org/10.1016/j.dsx.2018.10.010

Bruno, B. A., Choi, D., Thorpe, K. E., \& Yu, C. H. (2019). Relationship Among Diabetes Distress, Decisional Conflict, 
Quality of Life, and Patient Perception of Chronic Illness Care in a Cohort of Patients With Type 2 Diabetes and Other Comorbidities. Diabetes Care, 42(7), $1170 \quad$ LP $\quad-\quad 1177$. https://doi.org/10.2337/dc18-1256

Chery, M. (2018). Self- Care Management Education: Improving Diabetes Type 2 Patients' Health Outcomes Submitted by Marie Christine Judith Avignon-Chéry A Direct Practice Improvement Presented in Partial Fulfillment Of the Requirements for the Degree Doctor of Nursing Pr.

Dehghan, H., Charkazi, A., Kouchaki, G. M., \& Zadeh, B. P. (2017). General selfefficacy and diabetes management selfefficacy of diabetic patients referred to diabetes clinic of Aq, 10-14. https://doi.org/10.1186/s40200-0160285-z

Ebrahimi, H., Sadeghi, M., Amanpour, F., \& Vahedi, H. (2016). Evaluation of empowerment model on indicators of metabolic control in patients with type 2 diabetes, a randomized clinical trial study. Primary Care Diabetes, 10(2), 129-135.

https://doi.org/10.1016/j.pcd.2015.09.003

Fan, L. (2012). Examining the Feasibility, Acceptability and Effects of a Foot SelfCare Educational Intervention in Adult Patients with Diabetes at Low Risk for Foot Ulceration by. ProQuest. University of Toronto.

Fisher, L., Glasgow, R. E., Mullan, J. T., Skaff, M. M., \& Polonsky, W. H. (2008). Development of a brief diabetes distress screening instrument. Annals of Family Medicine, 6(3), $246-252$. https://doi.org/10.1370/afm.842

Gupta, S., Nayak, M., Sunitha, J., Dawar, G., Sinha, N., \& Rallan, N. (2017). Correlation of salivary glucose level with blood glucose level in diabetes mellitus. Journal of Oral and Maxillofacial Pathology, 21(3), 334. https://doi.org/10.4103/jomfp.JOMFP_2 $22 \_15$

Hilliard, M. E., Iturralde, E., WeissbergBenchell, J., \& Hood, K. K. (2017). The Diabetes Strengths and Resilience Measure for Adolescents with Type 1 Diabetes (DSTAR-Teen): Validation of a New, Brief Self-Report Measure. Journal of Pediatric Psychology, 42(9), 9951005.

https://doi.org/10.1093/jpepsy/jsx086

Hsieh, Y. L., Lee, F. H., Chen, C. L., Chang, M. F., \& Han, P. H. (2016). Factors Influencing Intention to Receive Examination of Diabetes Complications. Asian Nursing Research, 10(4), 289-294. https://doi.org/10.1016/j.anr.2016.10.004

Indonesia, I. N. I. of H. R. and D. (2018). Main Resulth of Baseline Health Research 2018. Jakarta: Ministry of Health of the Republic of Indonesia.

Jannoo, Z., \& Mamode Khan, N. (2019). Medication Adherence and Diabetes Self-Care Activities among Patients with Type 2 Diabetes Mellitus. Value in Health Regional Issues, 18(2018), 30-35. https://doi.org/10.1016/j.vhri.2018.06.00 3

Kim, G. M., Lim, J. Y., Kim, E. J., \& Park, S. M. (2019). Resilience of patients with chronic diseases: A systematic review. Health and Social Care in the Community, 27(4), 797-807. https://doi.org/10.1111/hsc.12620

Kim, J. Y., Ku, Y. S., Kim, H. J., Trinh, N. T., Kim, W., Jeong, B., ... Lee, K. E. (2019). Oral diabetes medication and risk of dementia in elderly patients with type 2 diabetes. Diabetes Research and Clinical Practice, 154(2019), 116-123. https://doi.org/10.1016/j.diabres.2019.07. 004

Kusnanto. (2017). Asuhan Keperawatan pada Klien dengan Diabetes Mellitus Pendekatan Holistic Care. Surabaya: AUP.

La Greca, A. (2004). Manual for the Self Care Inventory.

Lee, Y. J., Shin, S. J., Wang, R. H., Lin, K. Der, Lee, Y. L., \& Wang, Y. H. (2016). Pathways of empowerment perceptions, health literacy, self-efficacy, and selfcare behaviors to glycemic control in patients with type 2 diabetes mellitus. Patient Education and Counseling, 99(2), 287-294. https://doi.org/10.1016/j.pec.2015.08.021

Lefrancois, T., Mehta, K., Sullivan, V., Lin, S., \& Glazebrook, M. (2017). Evidence based review of literature on detriments to healing of diabetic foot ulcers. Foot and Ankle Surgery, 23(4), 215-224. https://doi.org/10.1016/J.FAS.2016.04.00 
2

Martinez, L. C., Sherling, D., \& Holley, A. (2019). The Screening and Prevention of Diabetes Mellitus. Primary Care Clinics in Office Practice, 46(1), 41-52. https://doi.org/10.1016/j.pop.2018.10.00 6

Masten, A. S. (2001). Ordinary magic: Resilience processes in development. American Psychologist, 56(3), 227-238. https://doi.org/10.1037/0003066X.56.3.227

Nawaz, M. S., Shah, K. U., Khan, T. M., Rehman, A. U., Rfile:///C:/Users/User/Downloads/Docu ments/martinez2018.pdfashid, H. U., Mahmood, S., ... Farrukh, M. J. (2017). Evaluation of current trends and recent development in insulin therapy for management of diabetes mellitus. Diabetes and Metabolic Syndrome: Clinical Research and Reviews, 11, S833-S839.

https://doi.org/10.1016/j.dsx.2017.07.003

Papatheodorou, K., Banach, M., Bekiari, E., Rizzo, M., \& Edmonds, M. (2018). Complications of Diabetes 2017. Journal of Diabetes Research, 2018, 1-4. https://doi.org/10.1155/2018/3086167

Schaper, N. C., Van Netten, J. J., Apelqvist, J., Lipsky, B. A., \& Bakker, K. (2017). Prevention and management of foot problems in diabetes: A Summary Guidance for Daily Practice 2015, based on the IWGDF guidance documents. Diabetes Research and Clinical Practice, 124, 84-92. https://doi.org/10.1016/j.diabres.2016.12. 007

Shao, H., Yang, S., Fonseca, V., Stoecker, C., \& Shi, L. (2019). Estimating Quality of Life Decrements Due to Diabetes Complications in the United States: The Health Utility Index (HUI) Diabetes Complication Equation. PharmacoEconomics, 37(7), 921-929. https://doi.org/10.1007/s40273-01900775-8

Shearman, C. P., \& Rawashdeh, M. (2016). Foot complications in patients with diabetes. Surgery (Oxford), 34(4), 192197.

https://doi.org/10.1016/j.mpsur.2010.02. 002

SPSS, I. (2019). IBM SPSS Statistics Vers 25.
Retrieved February 23, 2019, from https://www.ibm.com/iden/marketplace/spss-statistics/details

Stefanic, N., Caputi, P., Lane, L., \& Iverson, D. C. (2015). Exploring the nature of situational goal-based coping in earlystage breast cancer patients: A contextual approach. European Journal of Oncology Nursing, 19(6), 604-611. https://doi.org/10.1016/J.EJON.2015.03. 008

Steinhardt, M. A., Brown, S. A., Dubois, S. K., Harrison, L., Matthew Lehrer, H., \& Jaggars, S. S. (2015). A resilience intervention in African-American adults with type 2 diabetes. American Journal of Health Behavior, 39(4), 507-518. https://doi.org/10.5993/AJHB.39.4.7

Swoboda, C. M., Miller, C. K., \& Wills, C. E. (2017). Patient Education and Counseling Impact of a goal setting and decision support telephone coaching intervention on diet, psychosocial, and decision outcomes among people with type 2 diabetes. Patient Education and Counseling, (2016). https://doi.org/10.1016/j.pec.2017.02.007

Taormina, R. J. (2015). Adult Personal Resilience: A New Theory, New Measure, and Practical Implications. Psychological Thought, 8(1), 35-46. https://doi.org/10.5964/psyct.v8i1.126

Watkins, Y. J., Quinn, L. T., Ruggiero, L., Quinn, M. T., \& Choi, Y. ku. (2013). Spiritual and Religious Beliefs and Practices and Social Support's Relationship to Diabetes Self-Care Activities in African Americans. The Diabetes Educator, 39(2), 231-239. https://doi.org/10.1177/01457217134758 43

White, R. O., Eden, S., Wallston, K. A., Kripalani, S., Barto, S., Shintani, A., \& Rothman, R. L. (2015). Health communication, self-care, and treatment satisfaction among low-income diabetes patients in a public health setting. Patient Education and Counseling, 98(2), 144149.

https://doi.org/10.1016/j.pec.2014.10.019

Wiardani, N. K., \& Moviana, Y. (2015). Hubungan antara Tingkat Kepatuhan Diet dengan Kadar Glukosa dan Kolesterol Darah pada Penderita DM Tipe 2 di RSUP Sanglah Denpasar. 
Jurnal Ilmu Gizi, 6(2), 128-134.

Wilson, A. L., McNaughton, D., Meyer, S. B., \& Ward, P. R. (2017). Understanding the links between resilience and type-2 diabetes self-management: A qualitative study in South Australia. Archives of Public Health, 75(1), 1-13. https://doi.org/10.1186/s13690-0170222-8

Wingert, A., Johnson, N., \& Melton, S. T. (2015). Young Adults With Type 1 Diabetes. AADE in Practice, 3(2), 36-40. https://doi.org/10.1177/23251603155709 61 